\title{
Biosynthesis, Characterization, Antibacterial Activity and Anticancer Effect of Silver Nanoparticles Using Anethum Graveolens Leaf Extract
}

\author{
Vahab Alamdari-Palangi ${ }^{1}$, Alireza Shojazadeh ${ }^{2}$, Farnaz Hosseini ${ }^{3}$, Nesa Khalaf ${ }^{1}$, Aria \\ Dianatinasab $^{4 *}$, Mehrdad Ameri ${ }^{5 *}$ \\ ${ }^{1}$ Department of Medical Biotechnology, School of Advanced Medical Sciences and Technologies, Shiraz University of Medical Sciences Shiraz, Iran \\ ${ }^{2}$ Student Research Committee, Shiraz University of Medical Sciences, Shiraz, Iran \\ ${ }^{3}$ Department of Medical Nanotechnology, School of Advanced Medical Sciences and Technologies, Shiraz University of Medical Sciences, Shiraz, \\ Iran \\ ${ }^{4}$ Department of Biochemistry, School of Medicine, Shiraz University of Medical Sciences, Shiraz, Iran. \\ ${ }^{5}$ Diagnostic Laboratory Sciences and Technology Research Center, School of Paramedical Sciences, Shiraz University of Medical Sciences, Shiraz, \\ Iran
}

Received: 15/07/2020

Accepted: 27/09/2020

Published: 20/12/2020

\begin{abstract}
Nanoparticles are used in various fields of science, especially medicine. Advent of nanotechnology has led to significant development in disease diagnosis, treatment and drug delivery. Silver nanoparticles (Ag-NPs) play an important role in medical application, which makes them a viable alternative to common antibiotics. Amongst various methods, synthesis of Ag-NPs via green method has the advantage of being cost effective with no toxic agent. In this study, Spherical shape Ag-NPs with average size of $30 \mathrm{~nm}$ were synthetized using Anethum graveolens leaf extract as a green, cost-effective, non-toxic and environment-friendly source. Transmission electron microscopy (TEM), particle size analysis (PSA) and Fourier transform infrared (FT-IR) were performed to characterize synthesized Ag-NPs. The antibacterial activity of the synthetized Ag-NPs was evaluated against gram positive and negative bacterial pathogens. The minimum inhibitory concentration (MIC) at different concentrations of Ag-NPs were used to evaluate their antibacterial properties against Staphylococcus aureus, Enterococcus faecalis, Escherichia coli, and Pseudomonas aeruginosa pathogens. The results exhibited a desirable antibacterial property of Ag-NPs, suggested its usage as putative antibacterial agents. Moreover, the anticancer effect of green synthesized Ag-NPs was evaluated against MCF-7 lines and results showed that the cell viability is depended on the concentration of Ag-NPs. In short, this method provides a simple, cost effective and eco-friendly way to synthesis Ag-NPs which can be used as a suitable alternative to common antibiotics that use hazardous chemical agents, additionally, with anticancer effects against MCF-7 cells.
\end{abstract}

Keywords: Silver nanoparticles, Nanotechnology, Antibacterial agents, Anticancer effect

\section{Introduction}

Emergence of nanotechnology has attracted researchers in various fields of science and industries (1). Nanoparticles bridge the gap between bulk material, atomic and molecular structures. They have the potential to be used in medicine, hygiene, pharmacy, dentistry and etc., which is due to their interesting and unique physical and chemical properties such as optical, magnetic, mechanical and conductivity properties (2). Excessive use of antibiotics has led to microbial resistance; thus, many researchers have focused on development of novel and effective antimicrobial agents $(3,4)$. Several studies showed the antibacterial activity of Ag-NPs against a wide range of microorganisms $(5,6)$. Hence, they can be a promising compound in development of novel antimicrobial agents (7).
Nowadays, a great deal of efforts has been put into synthesis of Ag-NPs $(8,9)$. The Ag-NPs are being applied in cosmetic and hygiene products such as shampoos, soaps, toothpastes, anti-septic gels and pomades. Ag-NPs are generally synthesized using physical and chemical methods, but these approaches use toxic chemicals, organic solvents and non-biodegradable materials that are dangerous to human health and environment. Therefore, non-toxic, biocompatible, and eco-friendly methods to synthesize Ag-NPs are warranted $(10,11)$. Recent developments showed the critical role of plant extracts in production of Ag-NPs (12). Plants extracts contain several phenolic and antioxidant compounds that reduces $\mathrm{Ag}$ to Ag-NPs (13). There are several studies on the synthesis of AgNPs using various plants, such as Cupressus sempervirens Leaf

*Corresponding author: (a) Mehrdad Ameri, Diagnostic Laboratory Sciences and Technology Research Center, School of Paramedical Sciences, Shiraz University of Medical Sciences, Shiraz, Iran. Tel: +989386360918, Email address: mehrddameri@gmail.com and (b) Aria Dianatinasab, Department of Biochemistry, School of Medicine, Shiraz University of Medical Sciences, Shiraz, Iran. Email address: dianatinasab.aria@gmail.com 
(10) Givotia moluccana leaf (4), Syzygiumcumini fruit (14), Azadirachta indica aqueous leaf (15), Eriobotrya japonica leaf (16), aloe vera (17), Nigella sativa (18), Pistacia atlantica (13), Nyctanthes arbortristis (19), Orange and pineapple (20), and Pinus densiflor (21). Anethum graveolens (dill) is an annual herb and since antient time it has been exploited in ayurvedic medicines. Anethum graveolens is a member of Apiaceae family and rich in polyphenols, anti-oxidants and minerals (22). It is helpful in patients with hyperlipidemia (23) and as a component in gripe water, it can alleviate colic pain in babies and flatulence in young children (24). We used Anethum graveolens aqueous leaf extract to synthesize and evaluate antibacterial activity of Ag-NPs.

The main purpose of this study was to green synthesis of Ag-NPs, using Anethum graveolens leaf extract as an inexpensive, simple and non-hazardous BioSource. The antibacterial properties of resultant Ag-NPs were investigated against Staphylococcus aureus, Enterococcus faecalis, Escherichia coli, and Pseudomonas aeruginosa pathogens. Moreover, the anticancer effect of green synthesized Ag-NPs were evaluated against MCF-7 cells.

\section{Materials and methods \\ 2.1 Chemicals}

Silver nitrate (AgNO3, 99\%) was purchased from Sharlo (Spain). Before usage, the glassware was washed with $\mathrm{HCl}$ and deionized water. Ultrapure deionized water was used for synthesis reactions and leaves extraction.

\subsection{Leaf extract preparation}

A. graveolens leaves were collected from the countryside of Shiraz, Fars, Iran and an herbalist confirmed the species. The fresh plant leaves were washed with distilled water for several times (diH2O) to remove any dusts and mods. The leaves were shade dried at room temperature. To prepare leaf extract, $5 \mathrm{~g}$ dried leaf powder was boiled in $100 \mathrm{ml}$ deionized water for 15 min. Then mixture was filtered through a Whatman filter paper No.1. The filtered extract was stored at $4 \mathrm{oC}$, which was used for synthesis reaction.

\subsection{Ag-NPs synthesis}

For green synthesis, $1 \mathrm{ml}$ silver nitrate $(\mathrm{AgNO} \cdot 6 \mathrm{H} 2 \mathrm{O}, 0.1$ M) was added to $9 \mathrm{ml}$ leaves extract under vigorous stirring at room temperature. After $24 \mathrm{~h}$, the final mixture was centrifuged at $12000 \mathrm{rpm}$ for $5 \mathrm{~min}$. The obtained Ag-NPs was washed with deionized water and dried in an oven at $50^{\circ} \mathrm{C}$.

\subsection{Ag-NPs characterization}

Ag-NPs size and morphology were evaluated by TEM (Philips, CM 10; HT $100 \mathrm{Kv}$ ) and PSA. Functional groups of the phytochemicals, involved in the formation of Ag-NPs were analyzed using FTIR (Perkin- Elmer, Two).

\subsection{Antibacterial activity}

The synthesized Ag-NPs were tested for antimicrobial activity by evaluating MIC minimum inhibitory concentration (MIC) against gram-positive (Staphylococcus aureus ATCC 25923 and Enterococcus faecalis ATCC 29212) and gram negative (Escherichia coli ATCC 25922 and Pseudomonas aeruginosa ATCC 27853) pathogens. The bacteria were cultured in Muller-Hinton agar and fresh colonies were suspended in sterile water to reach their tarnish equivalent to $0.5 \mathrm{McF}$ arland. MIC with different concentration of Ag-NPs $(4,8,16, \ldots, 2048 \mu \mathrm{gr} / \mathrm{ml})$ was evaluated against $50 \mu \mathrm{l}$ of 1.5 $\times 106 \mathrm{CFU} / \mathrm{ml}$ bacterial suspension and cultured in Muller-
Hinton Broth medium. One Ag-NPs sample was used as the positive control and another with no bacteria as negative control.

\subsection{Anticancer effect}

To evaluate the anticancer effect of synthesized synthetized nanoparticles, five different concentration of Ag-NPs (6.25, $12.5,25,50,100 \mu \mathrm{gr} / \mathrm{ml}$ ) were exposed to MCF-7 cells for 24 hours. MCF-7 cell line which is a breast cancer cell line was purchased from Pasteur institute of Iran. At first, cancerous cells were cultured in RPMI1640 medium containing 10\% fetal bovine serum (FBS), $1 \%$ penicillin/streptomycin. Optimum condition for cell growth were considered as $5 \% \mathrm{CO}_{2}, 95 \%$ humidified atmosphere air and $37^{\circ} \mathrm{C}$ temperature. After subculture and cell count, we added 10000 cells to each well of a 48-well plate, additionally, cells were treated with different concentration of Ag-NPs. In addition to samples treated with silver nanoparticles, an untreated cell sample was considered as a control. After 24 hours of incubation (MTT) assay was performed to evaluate the effect of Ag-NPs on MCF-7 cells. Therefore, supernatant of each wells was extracted and while cells are attached at the bottom of wells, MTT was added to each well. After 4 hours of incubation in $37{ }^{\circ} \mathrm{C}$ and $5 \% \mathrm{CO}_{2}$ contents of each wells were removed and $50 \mu \mathrm{l}$ of DMSO was added to the wells. Consequently, after $30 \mathrm{~min}$ of incubation, the plate was read at $570 \mathrm{~nm}$ with an ELISA reader and the percentage of cell cytotoxicity was calculated using the optical density and the below formula:

$\%$ Cell viability $=(\mathrm{OD}$ value for test $/ \mathrm{OD}$ value for control) $\times 100$

\section{Results}

\section{1 synthesis of Ag-NPs}

After adding AgNO3 solution to the A. graveolens leaf extract, the color of mixture changed to dark brown. This alteration indicates the silver ions reduction to Ag-NPs.

\subsection{Characterization of synthetized Ag-NPs}

The TEM micrograph and PSA data of the synthesized AgNPs by $A$. graveolens extract are depicted in figure 1. TEM micrograph showed spherical Ag-NPs was surrounded by a thin layer of biological matrix from A. graveolens leaf extract. The particle size distribution of the biosynthesized Ag-NPs was in the range about $30 \mathrm{~nm}$. The PSA analysis showed that most $\mathrm{Ag}$ NPs had a size less than $100 \mathrm{~nm}$. It is worth noticing that PSA measures hydrodynamic diameter of nanoparticles, always reported larger size than TEM image. The FTIR analysis are exhibited in figure 2 . The band at $3417 \mathrm{~cm}^{-1}$ indicates the combined peaks of the amine or amide and $-\mathrm{OH}$ group stretching vibration in the plant extract. The methyl group gives its symmetric tensile vibrations of about $2863 \mathrm{~cm}^{-1}$ and asymmetric traction in $2922 \mathrm{~cm}^{-1}$. The peak at $1100 \mathrm{~cm}^{-1}$ was related to $\mathrm{C}-\mathrm{O}$ stretching. The peak at $1628 \mathrm{~cm}^{-1}$ (sp 2 hybridized $\mathrm{C}=\mathrm{C}$ ) can be assigned to the skeletal vibrations of the plant extract. Likely, the peak intensities in $1383 \mathrm{~cm}^{-1}$ is due to $\mathrm{C}-\mathrm{N}$ stretching in the extract of the plant capped silver nanoparticles. The peaks at 2322 and $2355 \mathrm{~cm}^{-1}$ are related to $\mathrm{N}-\mathrm{H}$ amine and amide group. This indicates the binding of $\mathrm{Ag}$ with $\mathrm{O}$ and $\mathrm{N}$ of $-\mathrm{OH}$ and $-\mathrm{NH} 2$ groups in the extract of the plant. 
a)

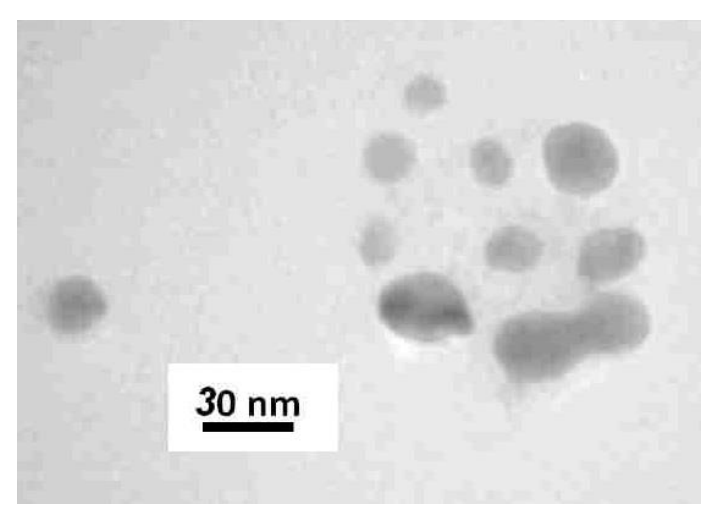

b)

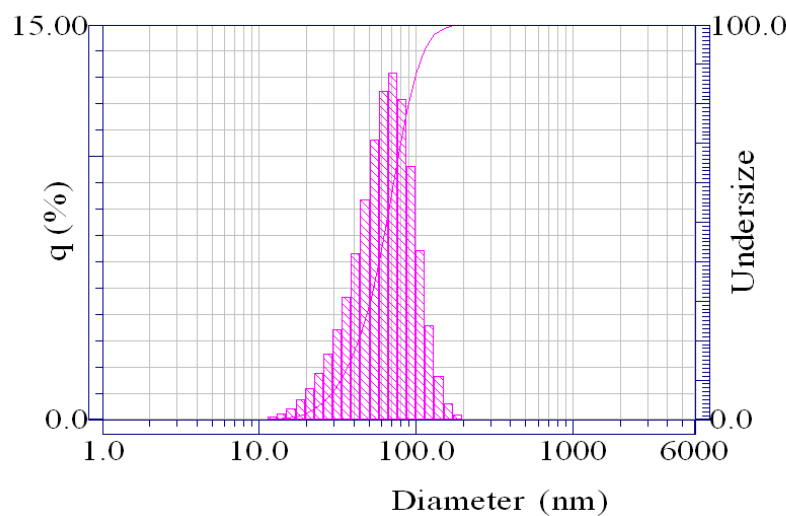

Figure 1: a) The approximate size and shape of synthetized Ag-NPs are shown in TEM micrograph. b) The PSA analysis of the Ag-NPs showed that the most of Ag-NPs have size less than $100 \mathrm{~nm}$

\subsection{The antibacterial activity of obtained Ag-NPs}

The antibacterial activity of the synthesized Ag-NPs against Staphylococcus aureus, Enterococcus faecalis, Escherichia coli, and Pseudomonas aeruginosa photogenes were evaluated. The lowest concentration of Ag-NPs ( $\mu \mathrm{gr} \mathrm{ml}^{-1}$ ) which prevented the visible growth of bacteria are reported as MIC in table 1. The results showed noticeable effect of synthesized AgNPs on the growth of these pathogens. The MIC of Ag-NPs against Escherichia coli and three other organisms were evaluated $64 \mu \mathrm{gr} \mathrm{ml} \mathrm{ml}^{-1}$ and $512 \mu \mathrm{gr} \mathrm{ml}^{-1}$, respectively. Consequently, it can be concluded that Escherichia coli was more sensitive than the other tested pathogens against synthetized Ag-NPs.

\subsection{The anticancer effect Ag-NPs on MCF-7 cell line}

The anticancer effect of five concentration $(6.25,12.5,25$, $50,100 \mu \mathrm{gr} / \mathrm{ml}$ ) of the synthesized Ag-NPs were evaluated against MCF-7 cell line using cell culture and MTT assay. After exposing each concentration of Ag-NPs with MCF-7 cells for $24 \mathrm{~h}$, cell viability was calculated using the optical density. MCF-7 cell treatment with Ag-NPs at 6.25, 12.5, 25, 50, 100 $\mu \mathrm{gr} / \mathrm{ml}$ concentration in $24 \mathrm{~h}$ reduced cell viability $60.40 \pm 0.83$ $\%, 48.70 \pm 0.49 \%, 35.54 \pm 0.78 \%, 21.78 \pm 0.39 \%, 11.14 \pm$ $0.13 \%$ respectively and cell viability for control sample calculated $100 \%$ after 24 hours. (Figure 3 ).

\section{Discussion}

The study results indicated that $A$. graveolens leaf extract can efficiently reduce the silver ions to Ag-NPs in a diameter range of $30 \mathrm{~nm}$, and prevented the aggregation of nanoparticles. Srinithya et al. (25) biosynthesized spherical Ag-NPs with a size of 10-30 nm. Raj et al. (26) synthesized Ag-NPs in a diameter ranging 2-20 $\mathrm{nm}$, and Arunachalam et al. (27) reported the biosynthesis of spherical Ag-NPs with a size range of $9-12 \mathrm{~nm}$.

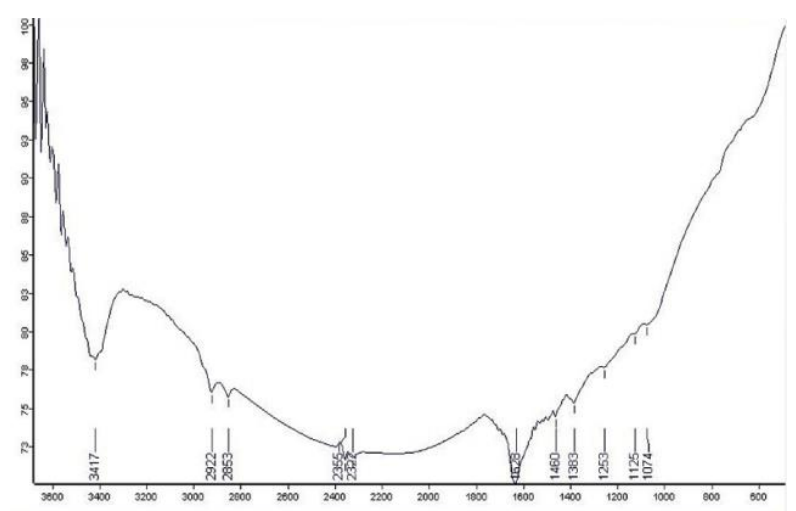

Figure 2: The FTIR spectra of synthesized Ag-NPs is illustrated. The standard peaks related to amine, amide and - $\mathrm{OH}$ groups appear at 3417 $\mathrm{cm}^{-1}$. The peaks at $2863 \mathrm{~cm}^{-1}$ (methyl), $2922 \mathrm{~cm}^{-1}$ (methyl), $1100 \mathrm{~cm}^{-1}$ (C-O), and $1628 \mathrm{~cm}^{-1}(\mathrm{C}=\mathrm{C})$ can be observed. The $\mathrm{C}-\mathrm{N}$ stretching caused an intensive peak at $1383 \mathrm{~cm}^{-1}$. The $\mathrm{N}-\mathrm{H}$ amine and amide group give the peaks at 2322 and $2355 \mathrm{~cm}^{-1}$

Table 1: Minimum inhibitory concentrations of Ag-NPs ( $\mu$ gr $\mathrm{ml}^{-1)}$ are evaluated against candidate bacteria

\begin{tabular}{lc}
\hline Strains & MIC \\
\hline E. coli & 64 \\
E. faecalis & 512 \\
P. aeruginosa & 512 \\
S. aureus & 512 \\
\hline
\end{tabular}

This study is a report about the synthesis of Ag-NPs by A. graveolens extract, their antibacterial activity and anticancer effect against some pathogenic bacteria and MCF-7 cell line respectively. In our study, TEM micrograph and PSA data were used to investigate the morphology, size and shape of Ag-NPs

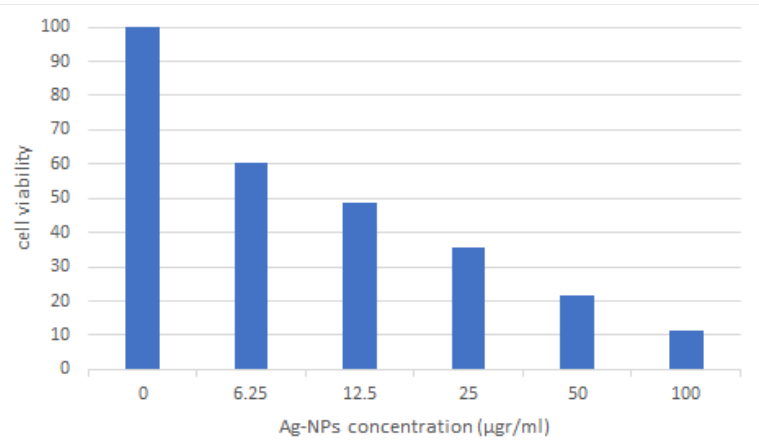

Figure 3: Cell viability of MCF-7 cells against different concentration of Ag-NPs after $24 \mathrm{~h}$. results are reported as \% cell viability compared with control sample

According to PSA analysis, the spherical nanoparticles with average size of $30 \mathrm{~nm}$ have desirable size distribution. The FTIR analysis was performed to identify the functional groups of biological compounds in the A. graveolens leaf extract that was involved in the reduction of Ag ions to Ag-NPs. FTIR analysis indicates the binding of $\mathrm{Ag}$ with $\mathrm{O}$ and $\mathrm{N}$ of $-\mathrm{OH}$ and $-\mathrm{NH} 2$ groups in the plant extract. 
Various studies showed antimicrobial activities of Ag-NPs against both Gram-negative and Gram-positive bacteria (7). In the present study, the antibacterial effect of Ag-NPs was evaluated against pathogenic strains such as E. coli, E. faecalis, $P$. aeruginosa and $S$. aureus. According to the results, synthesized Ag-NPs exhibited excellent antibacterial effect against these pathogenic bacteria. Based on MIC value reported in table 1, it can be concluded that Escherichia coli $\left(64 \mu \mathrm{gr} \mathrm{ml}^{-}\right.$ $\left.{ }^{1}\right)$ was more sensitive than the other tested pathogens $(512 \mu \mathrm{gr}$ $\mathrm{ml}^{-1}$ ) against synthetized Ag-NPs. These results are in line with previous studies. For example, Singhal et al. investigated antimicrobial properties of synthesized silver nanoparticles by Ocimum sanctum leaf extract. The MIC of biosynthesized silver nanoparticles was also measured using pathogenic bacteria such as E. coli $\left(0.314 \mu \mathrm{gr} \mathrm{ml}^{-1}\right)$ and S. aureus $(1.25 \mu \mathrm{gr}$ $\mathrm{ml}^{-1}$ ). Hence, results showed that Escherichia coli was more sensitive than S. aureus (28). Martınez-Castanon et al. (29) Synthetized $29 \mathrm{~nm}$ silver nanoparticles and reported MIC 13.02 and $16.67 \mu \mathrm{gr} \mathrm{ml}^{-1}$ for E. coli and S. aureus, respectively. It seems these differences might be due to particle size and bacterial strains $(29,30)$.

This inhibitory effect was due to different mechanisms. For example, Ag-NPs can be attached to the bacterial cell wall and infiltrate it. Therefore, these nanoparticles can produce reactive oxygen species (ROS) and free radicals in the bacterial cell, causing apoptosis and cell death (28). Anticancer effect of green synthesized silver nanoparticles with different leaf extracts have been reported recently $(31,32)$. Thus, we prepared five different concentration of synthesized Ag-NPs $(6.25,12.5,25,50,100 \mu \mathrm{gr} / \mathrm{ml})$ to evaluate their anticancer effect against MCF-7 cell line. Cell culture and MTT assay were used for this purpose. MTT assay is a colorimetric assay and reduction of MTT (yellow) to formazan (purple blue) is the basis of test. This reaction is mediated by a mitochondrial enzyme termed succinate dehydrogenates. The results of cell exposure to various concentration of Ag-NPs after $24 \mathrm{~h}$ indicated that the cell viability is depended on the concentration of silver nanoparticles. Highest concentration of Ag-NPs (100 $\mu \mathrm{gr} / \mathrm{ml})$ caused lower cell viability $(11.14 \pm 0.13 \%)$. A key strength of the present study was synthetizing Ag-NPs, using green synthesis, which is eco-friendlier and more cost effective in comparison to commonly used methods. However, there are some drawbacks and limitation when using this method to produce metal nanoparticles. Due to plant impurities, the size and size distribution was not controllable. The nanoparticles produced using green synthesis are sometimes less stable than the ones synthetized using chemical methods (33).

\section{Conclusions}

In this study, A. graveolens leaves extract is presented as a beneficial capping and reducing agent to synthesize Ag-NPs. The synthetized nanoparticles were stable even after several months and no change was observed visually. The obtained AgNPs were characterized using TEM, PSA, and FT-IR spectroscopy. The results showed spherical nanoparticles with approximately $30 \mathrm{~nm}$ in size and also desirable size distribution. The FT-IR analysis showed adding functional group to Ag-NPs. The analyses confirmed that the proposed green synthesis could be effective in synthetizing Ag-NPs. Also, the antibacterial activity of the Ag-NPs was analyzed against gram positive and negative pathogens. The results showed an intensive antibacterial property and bio-synthetized Ag-NPs can be used as a putative antibacterial agent. Moreover, we showed the anticancer effect of Ag-NPs is depended on the concentration of nanoparticles. For further researches, it is suggested to evaluate anticancer effects of green synthesized Ag-NPs against different cell lines, and antiinflammation studies can be implemented. Moreover, the antibacterial activity of the synthetized Ag-NPs should be investigated against other pathogenic bacterial strains.

\section{Aknowledgment}

The authors wish to thank Mr. H. Argasi at Research Consultation Center (RCC) of Shiraz University of Medical Sciences for his invaluable assistance in editing this manuscript. This study was supported by a grant from the Research Council of Shiraz University of Medical Sciences.

\section{Ethical issue}

Authors are aware of, and comply with, best practice in publication ethics specifically with regard to authorship (avoidance of guest authorship), dual submission, manipulation of figures, competing interests and compliance with policies on research ethics. Authors adhere to publication requirements that submitted work is original and has not been published elsewhere in any language.

\section{Competing interests}

The authors declare that there is no conflict of interest that would prejudice the impartiality of this scientific work.

\section{Authors' contribution}

All authors of this study have a complete contribution for data collection, data analyses and manuscript writing.

\section{References}

1. Sattarahmady N, Movahedpour A, Heli H, Hatam G. Gold nanoparticles-based biosensing of Leishmania major kDNA genome: visual and spectrophotometric detections. Sensors and Actuators B: Chemical. 2016;235:723-31.

2. Shabaninejad Z, Yousefi F, Movahedpour A, Ghasemi Y, Dokanehiifard S, Rezaei S, et al. Electrochemical-based biosensors for microRNA detection: Nanotechnology comes into view. Analytical biochemistry. 2019;581:113349.

3. Thombre RS, Shinde V, Thaiparambil E, Zende S, Mehta S. Antimicrobial activity and mechanism of inhibition of silver nanoparticles against extreme halophilic archaea. Frontiers in microbiology. 2016;7:1424.

4. Sana SS, Dogiparthi LK. Green synthesis of silver nanoparticles using Givotia moluccana leaf extract and evaluation of their antimicrobial activity. Materials Letters. 2018;226:47-51.

5. Kim S-H, Lee H-S, Ryu D-S, Choi S-J, Lee D-S. Antibacterial activity of silver-nanoparticles against Staphylococcus aureus and Escherichia coli. Korean J Microbiol Biotechnol. 2011;39(1):7785.

6. Sondi I, Salopek-Sondi B. Silver nanoparticles as antimicrobial agent: a case study on $\mathrm{E}$. coli as a model for Gram-negative bacteria. Journal of colloid and interface science. 2004;275(1):17782.

7. Siddiqi KS, Husen A, Rao RA. A review on biosynthesis of silver nanoparticles and their biocidal properties. Journal of nanobiotechnology. 2018;16(1):14

8. Franci G, Falanga A, Galdiero S, Palomba L, Rai M, Morelli G, et al. Silver nanoparticles as potential antibacterial agents. Molecules. 2015;20(5):8856-74.

9. Yan J, Abdelgawad AM, El-Naggar ME, Rojas OJ. Antibacterial activity of silver nanoparticles synthesized In-situ by solution spraying onto cellulose. Carbohydrate polymers. 2016;147:500-8.

10. Mousavi SM, Hashemi SA, Ghasemi Y, Atapour A, Amani AM, Savar Dashtaki A, et al. Green synthesis of silver nanoparticles toward bio and medical applications: review study. Artificial cells, nanomedicine, and biotechnology. 2018;46(sup3):S855-S72. 
11. Iravani S, Korbekandi H, Mirmohammadi SV, Zolfaghari B. Synthesis of silver nanoparticles: chemical, physical and biological methods. Research in pharmaceutical sciences. 2014;9(6):385.

12. Singh P, Kim Y-J, Zhang D, Yang D-C. Biological synthesis of nanoparticles from plants and microorganisms. Trends in biotechnology. 2016;34(7):588-99.

13. Sadeghi B, Rostami A, Momeni S. Facile green synthesis of silver nanoparticles using seed aqueous extract of Pistacia atlantica and its antibacterial activity. Spectrochimica Acta Part A: Molecular and Biomolecular Spectroscopy. 2015;134:326-32.

14. Mittal AK, Bhaumik J, Kumar S, Banerjee UC. Biosynthesis of silver nanoparticles: elucidation of prospective mechanism and therapeutic potential. Journal of Colloid and Interface Science. 2014;415:39-47.

15. Ahmed S, Saifullah, Ahmad M, Swami BL, Ikram S. Green synthesis of silver nanoparticles using Azadirachta indica aqueous leaf extract. Journal of radiation research and applied sciences. 2016;9(1):1-7.

16. Rao B, Tang R-C. Green synthesis of silver nanoparticles with antibacterial activities using aqueous Eriobotrya japonica leaf extract. Advances in natural sciences: Nanoscience and nanotechnology. 2017;8(1):015014.

17. Tippayawat P, Phromviyo N, Boueroy P, Chompoosor A. Green synthesis of silver nanoparticles in aloe vera plant extract prepared by a hydrothermal method and their synergistic antibacterial activity. PeerJ. 2016;4:e2589.

18. Amooaghaie R, Saeri MR, Azizi M. Synthesis, characterization and biocompatibility of silver nanoparticles synthesized from Nigella sativa leaf extract in comparison with chemical silver nanoparticles. Ecotoxicology and Environmental Safety. 2015;120:400-8

19. Gogoi N, Babu PJ, Mahanta C, Bora U. Green synthesis and characterization of silver nanoparticles using alcoholic flower extract of Nyctanthes arbortristis and in vitro investigation of their antibacterial and cytotoxic activities. Materials Science and Engineering: C. 2015;46:463-9.

20. Hyllested JÆ, Palanco ME, Hagen N, Mogensen KB, Kneipp K. Green preparation and spectroscopic characterization of plasmonic silver nanoparticles using fruits as reducing agents. Beilstein Journal of Nanotechnology. 2015;6(1):293-9.

21. Velmurugan P, Park J-H, Lee S-M, Jang J-S, Lee K-J, Han S-S, et al. Synthesis and characterization of nanosilver with antibacterial properties using Pinus densiflora young cone extract. Journal of Photochemistry and Photobiology B: Biology. 2015;147:63-8.

22. Jana S, Shekhawat GS. Anethum graveolens: An Indian traditional medicinal herb and spice. Pharmacogn Rev. 2010;4(8):179-84.

23. Mirhosseini M, Baradaran A, Rafieian-Kopaei M. Anethum graveolens and hyperlipidemia: A randomized clinical trial. J Res Med Sci. 2014;19(8):758-61.

24. Pulliah T. Medicinal plants in India. Regency Publ, New Delhi, India. 2002:137-9.

25. Srinithya B, Kumar VV, Vadivel V, Pemaiah B, Anthony SP, Muthuraman MS. Synthesis of biofunctionalized AgNPs using medicinally important Sida cordifolia leaf extract for enhanced antioxidant and anticancer activities. Materials Letters. 2016;170:101-4.

26. Raj DR, Prasanth S, Vineeshkumar T, Sudarsanakumar C. Surface plasmon resonance based fiber optic dopamine sensor using green synthesized silver nanoparticles. Sensors and Actuators B: Chemical. 2016;224:600-6.

27. Arunachalam K, Shanmuganathan B, Sreeja P, Parimelazhagan T. Phytosynthesis of silver nanoparticles using the leaves extract of Ficus talboti king and evaluation of antioxidant and antibacterial activities. Environmental Science and Pollution Research. 2015;22(22):18066-75.

28. Singhal G, Bhavesh R, Kasariya K, Sharma AR, Singh RP. Biosynthesis of silver nanoparticles using Ocimum sanctum (Tulsi) leaf extract and screening its antimicrobial activity. Journal of Nanoparticle Research. 2011;13(7):2981-8.

29. Martínez-Castañon G-A, Nino-Martinez N, Martinez-Gutierrez F, Martinez-Mendoza J, Ruiz F. Synthesis and antibacterial activity of silver nanoparticles with different sizes. Journal of nanoparticle research. 2008;10(8):1343-8.
30. Yazdi MET, Khara J, Sadeghnia HR, Bahabadi SE, Darroudi M. Biosynthesis, characterization, and antibacterial activity of silver nanoparticles using Rheum turkestanicum shoots extract. Research on Chemical Intermediates. 2018;44(2):1325-34

31. Al-Sheddi ES, Farshori NN, Al-Oqail MM, Al-Massarani SM, Saquib Q, Wahab R, et al. Anticancer Potential of Green Synthesized Silver Nanoparticles Using Extract of $<\mathrm{i}>$ Nepeta deflersiana $</ i>$ against Human Cervical Cancer Cells (HeLA). Bioinorganic Chemistry and Applications. 2018;2018:9390784.

32. Gomathi AC, Xavier Rajarathinam SR, Mohammed Sadiq A, Rajeshkumar S. Anticancer activity of silver nanoparticles synthesized using aqueous fruit shell extract of Tamarindus indica on MCF-7 human breast cancer cell line. Journal of Drug Delivery Science and Technology. 2020;55:101376.

33. Ahmad S, Munir S, Zeb N, Ullah A, Khan B, Ali J, et al. Green nanotechnology: a review on green synthesis of silver nanoparticles - an ecofriendly approach. International journal of nanomedicine. 2019;14:5087. 